\title{
Haveria um lugar conceitual e sistemático para a educação na filosofia de Fichte? Notas sobre o "Plano dedutivo" para a universidade de Berlim
}

\author{
Is there a conceptual and systematic place for education in Fichte's \\ philosophy? Notes on the "Deductive Plan" for the University of \\ Berlin
}

João Geraldo Martins da Cunha

jgmcunha@hotmail.com

(Universidade Federal de Lavras, Minas Gerais, Brasil)

\begin{abstract}
Resumo: Este trabalho defende a hipótese de que algumas posições sobre a educação apresentadas por Fichte em seu "Plano Dedutivo" para a universidade de Berlim podem ser inseridas sistematicamente em sua filosofia. Para tanto, articula três teses: (1) a necessidade de crítica da atividade docente e do funcionamento da universidade de então como uma instituição ultrapassada em relação aos propósitos de sua existência; (2) a prescrição da tarefa do intelectual frente a seu presente como exigindo dele um saber, ao mesmo tempo, filosófico e histórico; e (3) a suposição de que o exercício de crítica da razão é, ainda que não exclusivamente, "reflexionante".
\end{abstract}

Palavras-chave: Fichte; universidade; Keywords: Fichte; university; deduction;

dedução; tarefa intelectual; Juízo intellectual task; reflective judgment. reflexionante.
Abstract: This paper claims the hypothesis that some of the statements on education presented by Fichte in his "Deductive Plan" for the University of Berlin can be systematically inserted in his philosophy. To need to criticize the teaching activity and the functioning of the university at the time Fichte lived in as an outdated institution in relation to the purposes of its existence; (2) the prescription of the intellectual's task in the face of his present as demanding from him a philosophical and, at the same time, historical knowledge; and (3) the assumption that the exercise of the criticism of reason is, although not exclusively, "reflective". this end, it articulates three theses: (1) the

DOI: http://dx.doi.org/10.11606/issn.2318-9800.v25i2p51-66

Fichte enfrentou, diversas vezes e a partir de perspectivas distintas, explícita ou implicitamente, o tema da educação proposto para este encontro. Assim, seu projeto para a futura universidade de Berlim, ainda que escrito por encomenda (Léon, 1959, p.138-145), pode indicar algo da preocupação de Fichte nessa direção. Seu "Plano dedutivo" parece pretender inserir a demanda circunstancial e específica acerca das diretrizes para a construção daquela universidade numa reflexão bem mais ampla sobre o papel da educação na formação do cidadão. Refiro-me, por exemplo, ao fato de Fichte se demorar numa arriscada análise sobre o sistema de ensino em 
geral (não apenas universitário), ou sobre a articulação entre os diferentes níveis deste sistema, ou mesmo sobre a articulação entre pesquisa e ensino e, à luz de uma espécie de reforma educacional geral, propor mais especificamente seu projeto para a futura universidade de Berlim.

Tendo em vista a articulação esboçada entre o projeto de uma universidade e o quadro mais geral do ensino, talvez possamos entender melhor seu ousado e controverso título: "Plano dedutivo" (o grifo é meu). Entendo que, antes de indicar uma espécie de inferência stricto sensu, desde princípios transcendentais, acerca do empírico, talvez esse título possa sugerir uma “dedução” num sentido mais amplo. De tal forma que, embora a análise seja guiada por "princípios" mais gerais, a "dedução" teria a ver aqui, mais propriamente, com a relação entre o projeto de uma instituição e sua inserção no contexto social e político de seu tempo - em vista de princípios que poderiam delinear sua meta histórica. Este ponto será retomado abaixo, mas, desde logo, quero indicar o quanto, segundo minha hipótese de leitura, este projeto testemunha que a preocupação de Fichte com a educação ultrapassa as demandas mais imediatas que deram origem ao texto.

Em nome de minha afirmação inicial de que a educação está incluída entre as preocupações de Fichte (como tema filosófico), cabe ressaltar o papel central da educação nos Discursos à nação alemã (a meu ver, em estreita relação com este projeto); neste caso, como forma e meio para a construção da unidade alemã como nação. ${ }^{1}$ Assim, em pelo menos 5 dos 14 discursos que compõem esse texto, Fichte reflete sobre o papel e lugar estratégico de um projeto educacional em vista da superação, a médio e longo prazo, do cenário sombrio - para os "alemães" e para a humanidade em geral - das invasões napoleônicas.

Com este exemplo, eu pretendo indicar que, embora esparsa e difusa ao longo da obra, a preocupação com a educação pode ser pensada à luz de uma consideração, por assim dizer, mais "sistemática” em Fichte. Não poderei analisar exaustivamente esta hipótese em toda sua amplitude, mas creio poder oferecer argumentos em sua direção a partir de um recorte textual bem determinado, tomando em consideração algumas das afirmações de Fichte sobre o assunto no referido projeto para a futura universidade de Berlim.

Para ficar no caso específico do "Plano dedutivo", ainda hoje, a primeira impressão de leitura talvez seja a mesma que este projeto causou em um de seus críticos imediatos mais contundentes: Schleiermacher. Segundo o teólogo, a proposta de Fichte estaria encerrada numa espécie de contrassenso entre seu conteúdo e sua pretensão. De um lado, seu projeto teria sido delineado a partir de considerações,

1 Cf. Diogo Ferrer (2005, p.280): "Nação e educação são os dois mediadores fundamentais entre a ciência e o indivíduo, os vínculos que the permitem transitar da simples realidade natural para o conceito da uma humanidade universal, a qual permanece, apesar do aparente desvio representado pelos Discursos à Nação Alemã, a destinação do homem e a completação da razão". 
prima facie, avulsas e sem fundamentação conceitual mais rigorosa, como se Fichte estivesse escrevendo apenas por encomenda (e às pressas) e, por isso, manifestando opiniões idiossincráticas e meramente circunstanciais. ${ }^{2}$ Por outro lado, o tom pretensioso deste projeto - anunciado já em seu título, "Plano dedutivo" -, como que alheio ao conteúdo circunstancial de seu ponto de partida, seria suficiente para revelar seu caráter descabido e despropositado.

Certamente, o contexto de elaboração do "Plano dedutivo" não pode ser desconsiderado para a interpretação desse projeto (Léon, 1959, pp.134-160), mas pretendo mostrar que, mesmo assim, algumas de suas afirmações podem ter um alcance "sistemático" maior. Contrariamente a esta impressão inicial de leitura, inaugurada por Schleiermacher, defenderei uma interpretação do projeto de Fichte segundo a qual: (1) as considerações iniciais, de caráter mais geral sobre a educação e sobre o funcionamento das universidades, que preparam e justificam o delineamento específico da proposta para a universidade em questão - apresentado depois delas -, não são propriamente "circunstanciais", mas "históricas" (no sentido preciso que, como veremos, Fichte atribui a esta forma de análise); e (2), por isso mesmo, a elaboração de um "plano dedutivo", longe de expressar uma espécie de arrogância despropositada do filósofo diante da empiria, assume uma significação conceitual nada ingênua e intrinsecamente vinculada à tarefa - que, para Fichte, constitui um dever próprio ao intelectual - de diagnóstico do presente.

Assim, embora a pergunta sobre um possível "lugar conceitual e sistemático" para educação no pensamento de Fichte - expressa no título de meu trabalho - exija uma ampla consideração de seus mais diversos textos nos quais o tema aparece, estou convencido de que a interpretação que proponho para seu "Plano dedutivo" pode oferecer uma primeira resposta a ela.

Tendo em vista esta hipótese de leitura, posso delimitar a estrutura de minha argumentação a seguir como uma tentativa de articular três teses ou posições de Fichte: (1) a crítica da atividade docente e do funcionamento da universidade de então como uma instituição ultrapassada em relação aos propósitos de sua existência; (2) a prescrição da tarefa do intelectual frente a seu presente histórico como exigindo dele um saber, ao mesmo tempo, filosófico e histórico; e, por fim (3) a tese de que o exercício de crítica da razão é, notadamente, "reflexionante" - no sentido de uma reformulação do funcionamento do "juízo reflexionante" da terceira Crítica.

Para tanto, primeiramente apresentarei, muito sucintamente, algumas afirmações do "Plano dedutivo" visando mostrar algo da compreensão de Fichte

2 Essa, de fato, é a posição crítica de Schleiermacher, que leu previamente a proposta encaminhada por Fichte a Beyme (responsável pelos trabalhos preparatórios e que viria a ser substituído por Humboldt), no prefácio de sua própria contribuição. Essa posição é expressa no tom polêmico do título que Schleiermacher escolhe para sua própria proposta: "Pensamentos ocasionais sobre as universidades no sentido alemão" (Gelegentliche Gedanken Über Universitäten in Deutschen Sinn). 
sobre a educação. Depois, recuperando um texto dos anos de lena, ${ }^{3}$ quero mostrar em qual sentido considero que estas asserções do "Plano" podem ser lidas como expressão in concreto da atividade intelectual que o próprio Fichte prescrevia como "tarefa" e "destinação" para o filósofo nas Preleções de 1794. Por fim, tentarei mostrar uma possível fundamentação do exercício desta tarefa do intelectual a partir do uso reflexionante da razão, como uma de suas condições transcendentais de possibilidade.

Dentre as diversas afirmações polêmicas deFichte, destaco três posicionamentos sobre a educação relevantes para meu argumento. (1) Em primeiro lugar, Fichte sustenta que o ensino universitário deveria estar articulado com os momentos anteriores da formação educacional, pois apenas deste modo a universidade poderia cumprir seu papel histórico e político na constituição da sociedade na qual se insere. (2) Em segundo lugar, para cumprir essa função que the seria própria, também o modo de funcionamento da universidade precisaria ser revisto. Nessa direção, Fichte afirma que a docência universitária deveria ser "dialógica" ou "socrática" e não uma espécie de reprodução mecânica de manuais que impediria tanto a interação entre professor e aluno, quanto (e por isso mesmo) o exercício reflexivo que torna, a seus olhos, o pensamento "vivo". (3) Por fim, paralelamente a este método "socrático" de ensino, deveria ser estimulada uma interação entre professores na forma de seminários. Vejamos como estas três posições se inserem no percurso geral dos argumentos de Fichte no "Plano dedutivo".

0 projeto apresentado por Fichte está divido em três seções: inicialmente, ele apresenta um conceito geral de universidade à luz das condições históricas (§ 1-13); em seguida, indica os principais mecanismos pelos quais esse conceito poderia ser realizado tendo em vista as condições empiricamente dadas - "de tempo e lugar" - (§ 14-57); por fim, define os meios pelos quais uma instituição, assim definida, poderia influenciar o "universo científico" (\$ 58-67).

Uma maneira de interpretar a articulação entre estas três partes pode se dar a partir do conceito central de "aplicação" (Anwendung), tão recorrente nos textos do período de Berlim. ${ }^{4}$ Neste caso, talvez possamos sugerir que estes três passos

3 Não posso apresentar aqui as razões pelas quais entendo que podemos assumir alguma forma de continuidade entre os textos dos diferentes "períodos" da produção de Fichte. De todo modo, esta ausência não tem maiores repercussões para meu argumento uma vez que, mesmo em Berlim, o tema elaborado nos anos de lena reaparece na forma da vinculação entre filosofia e vida de maneira central.

4 Cabe lembrar que, embora a noção de "filosofia aplicada" seja própria aos textos tardios, a noção de "aplicação" como parte do método filosófico é anterior. Como prova disso, basta considerar o modo decisivo pelo qual a "aplicação" comparece nas divisões gerais do Fundamento do direito natural de 1796. 
pretendem, de certo modo, constituir uma espécie de "aplicação" direita de algumas das teses sobre educação presentes nos Discursos à nação alemã. Sem pretender enfrentar os diversos aspectos envolvidos no tema da "aplicação" em Fichte, posso apenas ressaltar o quanto, neste caso específico pelo menos, o movimento argumentativo parece mostrar que, neste "Plano", Fichte estaria tentando colocar em prática uma das funções que, alhures, defende ser a tarefa do intelectual frente a seu presente histórico.

De todo modo, os títulos das seções contribuem para a interpretação que defendo aqui da noção de “dedução", notadamente, segundo a qual essa última não designa o procedimento de inferências particulares a partir de princípios especulativos gerais. Em outra direção, esta “dedução” parece apontar, mais propriamente, para o fato de que, como intelectual (Gelehrte), o filósofo deve pensar seu presente.

É nesta direção que interpreto o fato de Fichte começar sua proposta com um diagnóstico de seu tempo, particularmente no que diz respeito ao funcionamento das instituições universitárias, que ainda permaneceriam presas aos moldes segundo os quais teriam surgido. Assim, em sua origem histórica, com escassez de bibliotecas e sem a facilidade para a publicação de livros, elas cumpriram o importante papel de divulgação do saber em seus diferentes ramos. Presas à sua origem, as universidades manteriam um funcionamento que não teria mais razão de ser, ou melhor, não teriam “direito à existência” (SW, VIII, 100). Assim, as posições de Fichte que apresentei acima (articulação entre os níveis de ensino, mudança no método de ensino e a necessidade dos seminários de pesquisa) podem ser lidas e interpretadas à luz deste diagnóstico geral.

Para cumprir uma função à altura de seu tempo, a instituição universitária deveria, em primeiro lugar, se articular com os estágios anteriores da formação educacional dos cidadãos. Neste caso, em vista de sua função nos quadros sociais da educação, ela poderá operar como uma "escola da arte do uso científico do entendimento” (SW, VIII, 102). Mas a articulação com os outros níveis de ensino é apenas um dos aspectos a serem considerados para que a universidade possa cumprir seu papel. Cabe, além disso, repensar seu modo de funcionamento e aqui chegamos ao segundo posicionamento de Fichte indicado acima.

A universidade deve modificar radicalmente seu funcionamento quanto ao exercício da docência. Seu ensino não deve mais ser o lugar para reprodução mecânica de conteúdos (a imprensa e as bibliotecas podem cumprir este papel), mas, antes, ser praticado segundo um método “socrático". Para que tenha lugar a "arte da crítica” (SW, VIII, 103) - principal objetivo da formação universitária -, o professor deve executar seu plano de ensino a partir da mediação dos questionamentos de seus estudantes. Apenas esta interação "socrática" poderia tornar possível um aprendizado "reflexivo" e uma apropriação crítica dos conteúdos. Em outras palavras, 
talvez possamos dizer que, para que o aprendizado passe da reprodução mecânica da "letra" para a incorporação crítica do "espírito" do saber, "o professor deve perceber as necessidades imediatas do aluno", enfrentando suas questões. Apenas assim:

0 ensino científico passa da forma de simples apresentação contínua, tal como está nos livros, para a forma do diálogo; por conseguinte, constrói-se a verdadeira academia, no sentido de escola socrática (SW, VIII, 104).

Com este matiz, Fichte parece indicar não apenas o papel de ensino desta instituição, mas também sua importância como instituição de pesquisa. Afinal, com esta mudança metodológica, o ensino poderia fomentar a pesquisa e o progresso científico. E é nessa mesma direção que, creio eu, possamos interpretar a terceira afirmação de Fichte apontada acima sobre a importância de seminários entre professores. A meu juízo, Fichte articula em diversos níveis a interação da comunidade acadêmica em vista do fomento simultâneo ao ensino e à pesquisa. Assim, o exercício "dialógico" da docência supõe um papel mais ativo do aluno no desenvolvimento de seus estudos. É no quadro de interações em diversos níveis que os seminários podem ocupar seu lugar em vista do aprimoramento da pesquisa. Como afirma Fichte, "tal viveiro de artistas, segundo diferentes graus desta arte, em seu ponto mais alto, seria um seminário de professores" (SW, VIII, 115).

Até aqui, tentei apenas esclarecer o sentido daquelas três afirmações de Fichte sobre a educação, especificamente em relação ao modo de funcionamento e propósito da universidade. Retomando meu ponto de partida, cabe, pois, perguntar: seriam estas afirmações apenas anedóticas e meramente circunstanciais? Entendo que não, e, para defender minha posição, pretendo mostrar como elas se articulam com, pelo menos, dois aspectos do pensamento de Fichte - a serem analisados nos dois próximos passos deste trabalho. Vejamos o primeiro deles.

III

Em linhas gerais, o que defenderei agora é que podemos analisar estas três posições da proposta de Fichte, em especial, à luz do que ele considera ser a tarefa do intelectual. Mais exatamente, entendo que o "Plano" possa ser lido como uma tentativa, in concreto, da atuação de Fichte segundo o que ele próprio designa, em outro contexto, como "tarefa" própria ao intelectual.

Para o esclarecimento deste ponto, gostaria de retomar alguns aspectos da caracterização que Fichte fez desta tarefa num texto de 1794: Preleções sobre $a$ destinação do sábio. ${ }^{5}$ É bem verdade que Fichte desenvolveu este tema em outros

5 Não posso me deter aqui em considerações sobre as dificuldades de tradução deste título, notadamente em relação aos termos "Bestimmung" e "Gelehrte". Em português, é comum a versão por, respectivamente, "destinação" ou "destino" e "sábio" ou "erudito". Prefiro as primeiras opções 
momentos de sua trajetória (o que não deixa de ressaltar a importância da educação como preocupação constante sem seu pensamento), mas considero que o texto dos anos de lena indica mais claramente o ponto que quero ressaltar.

Em linhas gerais, a caracterização da tarefa do intelectual como um saber, ao mesmo tempo, filosófico, histórico-filosófico e histórico vai fornecer a chave pela qual o "Plano dedutivo" pode ser considerado. Mais exatamente, entendo que a “dedução" indicada no título, como já sugeri, pode ser lida num sentido mais amplo do que a simples consideração - muito frequentemente, maliciosa e pejorativa - de "inferência" silogística de premissas especulativas para alguma conclusão particular e empírica. Nestes termos, o projeto de Fichte não merece a repreensão sumária e genérica, que podemos rotular como "idealismo", de ter pretendido "deduzir" o empírico da razão; a universidade da Wissenschaftslehre. A conexão entre princípios sistemáticos e filosóficos com a realidade empírica mais imediata depende de diversas mediações.

Elementos como a ideia da destinação moral da humanidade, o processo de esclarecimento progressivo da consciência do saber, ou ainda, o fim último da vida social e política certamente estão presentes e contribuem decisivamente para a elaboração do "Plano". Mas, quero insistir, não na forma de uma espécie de “dedução" do empírico a partir de premissas especulativas. Pelo contrário, entendo que Fichte aposta numa possível "dedução" do desenho institucional da universidade de Berlim articulando elementos especulativos com um esforço de interpretação ou diagnóstico de seu presente. Nesse sentido, na seção anterior, vimos como seu ponto de partida é um diagnóstico sobre o funcionamento contemporâneo das universidades, seguido de sua crítica, com base em elementos históricos; e, por fim, a tentativa do delineamento de como esta instituição poderia cumprir seu papel no interior da comunidade política na qual se insere.

Enfim, como entender a partilha entre transcendental e empírico no desenho do projeto institucional proposto por Fichte? É bem verdade que a sistematicidade do saber é uma constante central em seu pensamento, mas, nem por isso, a tarefa que ele se propôs como intelectual exclui a consideração de elementos empíricos (sociais e históricos) como parte dela. Vejamos o que as Preleções sobre a destinação do sábio (de 1794) dizem sobre isso.

Preliminarmente, devo chamar atenção para o tema da intersubjetividade ali presente - quiçá, de maneira inédita. Uma das teses centrais da segunda Preleção, sobre a “destinação do homem em sociedade”, é aquela de que nossa identidade só pode ser alcançada pela mediação com o outro (e sua liberdade). Embora embrionária

(destinação e sábio), muito sumariamente, pelo fato de que a primeira opção indica o movimento e não um "fato" (destino); por outro lado, a noção de erudito parece carregada de um sentido que Fichte, a meu ver, pretende expressamente criticar como "erudição vazia". Para todos os efeitos, aqui empregarei os vocabulários "sábio" e "intelectual” sem diferenciá-los. 
(Oncina e Ramos Valera, 2002, p.18), essa "dedução" da intersubjetividade já é indicativa do caráter interativo da razão em Fichte. Nesse sentido, longe de indicar uma espécie de opinião anedótica, a delimitação da atividade de ensino, segundo um método "dialógico", expressa, em outro registro de análise, o traço especulativo mais elementar da razão em Fichte. ${ }^{6}$

Mas o ponto central de articulação entre aquelas posições sobre a educação do "Plano dedutivo" (indicadas acima) e estas Preleções, a meu ver, incide, mais diretamente, sobre outro aspecto: elas expressam o compromisso entre o intelectual e seu presente. Como intelectual, o filósofo Fichte teve de articular premissas especulativas (próprias à "filosofia") com um saber "histórico".

Aproximando os dois textos, podemos perceber, por exemplo, que aquela proposta do "método dialógico" deriva muito claramente da importância da capacidade de comunicação do intelectual. A obrigação que, nas Preleções, vincula o intelectual à sociedade em termos mais gerais, agora é pensada especificamente quanto ao exercício da docência. 0 docente deve se comunicar com seus alunos (segundo aquele "método dialógico") em vista de uma performance pedagógica, que, no fundo, é a mais condizente com sua tarefa como intelectual. Um ensino "reflexivo" (e não "mecânico"), fomentado por este método, é exigido quando se pretende formar intelectuais, no sentido definido pelas Preleções. Neste caso, a capacidade de comunicação se torna uma virtude essencial do intelectual, uma vez que, diz Fichte, mais do que qualquer outro estamento (Stand), a função dos intelectuais só pode ser determinada em vista da sociedade da qual faz parte: "O sábio (Gelehrte) está destinado à sociedade; na medida em que é um sábio, seu estamento, mais do que qualquer outro, existe propriamente apenas por e para a sociedade" (SW, VI, 330).

Chegamos aqui ao ponto mais decisivo no que diz respeito à vinculação daquelas teses sobre a educação e a compreensão que Fichte tem da tarefa do intelectual pelo menos, segundo estas Preleções. A quarta delas descreve a tarefa do intelectual como um saber ao mesmo tempo filosófico, histórico-filosófico e histórico.

O saber intelectual não é apenas "filosófico", mas deve ser, ao mesmo tempo: histórico-filosófico e histórico. Na medida em que sua proposta para a universidade de Berlim responde ao compromisso que o intelectual deve assumir no exercício de sua "tarefa", Fichte não poderia restringir suas considerações a uma "dedução", por assim dizer, silogística. A coerência e articulação de suas afirmações devem, segundo o que acabo de apresentar, levar em conta elementos empíricos. Por isso mesmo, segundo minha leitura, Fichte começar seu "Plano" com um diagnóstico histórico sobre as universidades e seu papel social - como vimos acima.

6 Ressalto ainda que a intersubjetividade consta em diversos outros textos de Fichte, para além do modo ainda "embrionário" pelo qual aparece nestas Lições. 
Grosso modo, a quarta Preleção, dedicada ao tema específico da destinação ou vocação do sábio ou intelectual, atesta que o exercício intelectual de crítica da razão, para Fichte, implica assumir o presente como problema filosófico incontornável. Em linhas gerais, o papel do intelectual é delineado a partir de sua ponderação sobre as necessidades e os anseios nascidos e fomentados pela interação social; ou seja, cabe a ele refletir e indicar se e o quanto sua sociedade é mais ou menos "perfeita" (Vollkommenheit); isto é, se ela está organizada de modo a promover o desenvolvimento e satisfação de todos os carecimentos (aller Bedürfnisse) de maneira uniforme (gleichförmige). Mas, então, em que consiste o conhecimento que torna possível o cumprimento desta tarefa intelectual?

Como indicado acima: ele deve ser filosófico (como saber das disposições e carecimentos humanos); deve ser também "histórico-filosófico", como saber dos meios necessários para a satisfação daquelas necessidades e carecimentos (sem o qual o conhecimento filosófico seria estéril e sem utilidade social); por fim, ele deve ser ainda histórico. Diz Fichte:

Pressupondo apenas princípios racionais e unicamente sob a suposição de uma experiência em geral, anterior a qualquer experiência determinada, podemos, sem dúvida, calcular o curso que seguirá o gênero humano. (...) Mas é impossível determinar o nível no qual se encontra a sociedade em determinado momento com base meramente na razão. Para tanto, devemos consultar também a experiência, estudar os acontecimentos passados (segundo diretrizes filosóficas) (...); este conhecimento é histórico (SW, VI, 328).

Em suma, a sabedoria (Gelehrsamkeit) exigida do intelectual é composta pelas três dimensões apresentadas: saber filosófico (dos princípios); saber históricofilosófico (da história); saber histórico (do presente). Por outro lado, como vimos, o "conceito" de universidade é elaborado, no "Plano Dedutivo", a partir de uma referência constante às condições históricas (do passado e do presente), explicitamente enunciadas nos títulos de suas seções.

A partir destas muito breves indicações sobre as Preleções de lena, eu quero reiterar dois pontos: (1) o "Plano dedutivo" parece responder a uma tarefa própria ao exercício intelectual do filósofo Fichte, mesmo que sua motivação empírica tenha advindo de uma demanda circunstancial - do fato que a demanda seja circunstancial não decorre que a resposta filosófica o seja, pois, para Fichte (segundo as Preleções) o presente é tema filosófico -; (2) por isso mesmo, a “dedução” sugerida pelo título não parece justificar a acusação segundo a qual ele estaria, presunçosamente, inferindo ("silogisticamente"?) a empiria. A coerência exigida do saber, desde o pressuposto de sua sistematicidade, não implica, para Fichte (conforme a citação anterior, por exemplo) que premissas transcendentais ou especulativas da razão sejam suficientes para determinar a experiência empírica; embora necessárias, elas são não suficientes, 
e, por isso mesmo, o cumprimento da tarefa intelectual pressupõe as três dimensões do saber que, como visto, extravasam a especulação filosófica stricto sensu.

Como conclusão parcial, entendo, pois, que podemos até discordar da concepção de ensino e de universidade proposta por Fichte naquele "Plano", mas não podemos deixar de reconhecer que seu esforço mostra o compromisso com a "tarefa" que ele próprio designa ao intelectual. Nesse sentido, sua resposta a uma demanda circunstancial não terá pretendido ser, ela mesma, circunstancial; nem, por outro lado, uma “dedução" presunçosa e ingênua. ${ }^{7}$

$\mathrm{Na}$ parte final de minha exposição, gostaria de perguntar pelas condições de possibilidade daquele saber requerido pela atividade intelectual. Com isso pretendo apresentar um segundo aspecto pelo qual aquelas posições do "Plano dedutivo" podem ser articuladas sistematicamente com o projeto filosófico de Fichte.

IV

O tema envolvido na questão acima é dos mais intrincados, a começar pelo fato de que, quando abordou diretamente o problema do "método" adequado à exposição filosófica, Fichte pareceu sustentar posições muito diferentes e, quase sempre, nada compatíveis entre si (Breazeale, 2001, p.20). Diante disso, poderei aqui apenas sugerir uma possível direção para o encaminhamento da questão, retomando um traço da herança kantiana sobre o pensamento de Fichte - notadamente, em relação ao período de lena, no qual foram publicadas as Lições comentadas acima.

Em favor da tese de que a "dedução" do projeto para a universidade de Berlim não se resume a uma espécie de inferência silogística (e "idealista" no sentido algo pejorativo que the foi atribuído por seus detratores), gostaria de salientar a importância que o tema da "reflexão" teve para Fichte. Em outras palavras, penso que uma das condições de possibilidade para a execução da tarefa do intelectual - como articulação do saber filosófico e histórico - pode ser recuperada a partir de uma noção muito peculiar que a "reflexão" pode ter para Fichte - leitor da terceira Crítica de Kant.

Em carta ao amigo Weisshuhn, voltando de um período na Suíça (1790-1), Fichte declara que tem se ocupado da terceira Crítica e que ela the parece ser a mais difícil das três, particularmente quanto a sua Introdução: "a parte mais obscura do livro". Em seguida faz uma análise do parágrafo II ("Do domínio da filosofia em geral"), onde é trabalhada "a união entre as leis da natureza e leis da liberdade". Além disso, concentra sua atenção na afirmação de Kant segundo a qual o elemento

7 Sobre o quanto os leitores de Fichte teriam sido influenciados por Jacobi, Reinhold, Schelling e Hegel e "atribuído a ele o insano projeto de pretender criar o mundo partindo eu", cf. Ives Radrizzani (2016, p.229). 
de "união" entre essas duas esferas deve ser "mais profundo que o princípio da natureza e o da liberdade"; “mais profundo", pois se pretende evitar um duplo paradoxo: ou bem, a liberdade ser pensada sob o conceito de natureza, ou bem, a natureza ser suprimida, por assim dizer, pela liberdade.

Ora, no movimento argumentativo da Introdução, o "princípio mais profundo" é apresentado por Kant através de um "termo médio entre entendimento e razão" (Ak. B p. xxi), a saber: o Juízo (Urteilskraft); ${ }^{\circ}$ o qual, embora não corresponda a uma "legislação própria" (eigene Gesetzgebung), pode desempenhar este papel. No parágrafo IV desta mesma Introdução, podemos encontrar a explicação do modo pelo qual o Juízo poderia cumprir essa tarefa de mediação para Kant. Eis o locus da distinção entre "juízo determinante" (bestimmende Urteilskraft) e "juízo reflexionante" (reflektierende Urteilskraft) tão cara ao delineamento final do projeto crítico de Kant e, talvez, uma das heranças mais incisivas desse projeto sobre a elaboração inicial da $W$ - $L$ de Fichte.

Particularmente, quero insistir num único ponto do argumento de Kant em vista do problema formulado acima. Lemos que o "campo da crítica se estende a todas as pretensões das faculdades, para pô-las nos limites de sua legitimidade" ( $A k$. $B$, pp.xx-xxi). Dessa forma, também as pretensões do exercício do Juízo deverão ser submetidas ao tribunal da crítica e, por essa via, poderemos responder pelo fundamento de unidade entre entendimento e razão. Assim, a despeito do "abismo" (Kluft) entre natureza e liberdade, ipso facto, nada impede que se defenda alguma "passagem" (Übergang) - legitimada criticamente - entre os dois domínios; e a análise do Juízo poderá oferecer os elementos para se pensar criticamente essa passagem.

Insisto, porém, tendo em vista a leitura que Fichte fez do texto de Kant, na formulação do problema que leva à necessidade de se pensar criticamente esta mediação. Diz Kant:

o conceito de liberdade deve tornar efetivo no mundo sensível o fim dado por suas leis; e a natureza, por conseguinte, também tem de ser pensada de maneira que a legalidade de sua forma esteja de acordo pelo menos com a possibilidade dos fins a serem nela efetivados de acordo com a liberdade (Ak. B pp.xix-xx; o grifo é meu).

A solução apresentada por Kant consiste, dito muito sumariamente, na defesa de um uso legítimo do Juízo, paralelamente àquele pelo qual podemos determinar

8 A disputa sobre a melhor tradução para este termo é conhecida (e, talvez, interminável). Sigo aqui a opção de Rubens R. Torres Filho - Juízo - (Kant, 1995), em detrimento, por exemplo, daquela de Fernando C. Mattos - Faculdade de Julgar - (Kant, 2016). De todo modo, o mais importante para mim é destacar uma distinção entre dois exercícios judicativos: "O Vermögen zu urteilen, especificado segundo as formas lógicas pelas quais Kant monta a tábua, poderia, então, ser considerado como uma possibilidade ou potencialidade de formar juízos, e a Urteilskraft, cujo exercício será exposto tanto no Sistema dos princípios da primeira Crítica quanto na Crítica da faculdade de julgar (Kritik der Urteilskraft), constituiria a efetuação ou ativação em relação com as afecções sensíveis" (Longuenesse, 1993, p. xiv). 
o particular sob um universal. Quando emite juízos empíricos ou juízos sintéticos a priori que fundamentam a ciência natural e a matemática, nosso entendimento subsume casos a regras, fazendo uso de juízos determinantes. A novidade desta Introdução da terceira Crítica, que parece ter instigado Fichte, é que também seria criticamente legítimo "ascender do particular na natureza ao universal" (Ak. B, p. xxvii), por meio do Juízo reflexionante.

Em vista de meu propósito aqui, permito-me interpretar esta tese de Kant muito sumariamente. Quando julgamos um edifício belo (o exemplo é de Kant, $A k$. p. 19), não queremos nem apenas dizer que ele é, para mim, belo, ${ }^{9}$ nem podemos partir de um suposto conceito universal de belo (alcançado previamente: ou a partir da construção de conceitos empíricos - por abstração, comparação e reflexão -; ou deduzido como categoria do entendimento) ao qual subsumimos o edifício em questão. Não sendo nem conceito empírico, nem categoria, o predicado belo só pode ser entendido a partir de outra pretensão da atividade judicativa que não é a determinação do particular sob um universal; pela qual o "belo" só pode ocupar o lugar de "ideia" (Ak. 25-26).

Este outro exercício judicativo possível consiste, pois, na "ascensão do particular ao universal" de que fala a Introdução. É notável como Kant articula este processo reflexivo com a "capacidade universal de comunicação" (Ak. 27). Ainda que eu não tenha a pretensão de determinar cognitivamente o edifício à minha frente, ao emitir o juízo de que ele é belo, também não pretendo apenas expressar um gosto peculiar. Tudo se passa como se eu almejasse que o outro reconhecesse minha pretensão à universalidade desta ideia.

Mas o que pode legitimar criticamente esta pretensão? Para dizer numa palavra: é a "comunicabilidade universal subjetiva". De tal modo que a "reflexão" sucessiva e assintótica sobre os casos, ainda que não permita e legitime uma "ciência do belo", autoriza, porém, uma "crítica do belo" (Ak. 177). Passando ao largo das dificuldades e matizes do argumento de Kant, cuja reconstrução nos desviaria demasiadamente dos objetivos deste trabalho, retomemos nossa questão à luz destas considerações gerais.

Mutatis mutandis, ao exigir do intelectual um saber não apenas "filosófico", mas também "histórico", segundo as Preleções, Fichte parece recuperar, ainda que implícita e muito indiretamente, a importância deste uso reflexivo do Juízo.

Consideremos, por exemplo, o fato de que "o intelectual está destinado primordialmente à sociedade" (SW, VI, 330), particularmente por meio de um compromisso com a ideia de "justiça social" (o termo não é de Fichte), na medida em que deve cuidar do cumprimento das condições pelas quais as necessidades e impulsos humanos possam ser distributivamente atendidos socialmente. Para tanto,

9 Nesse sentido, ele difere do juízo de gosto: “o vinho espumante das Canárias é agradável”. 
por sua vez, se faz necessário um saber que não é apenas "filosófico" no sentido estrito, pois "é impossível determinar o nível em que se encontra uma sociedade em certo momento baseando-se apenas na razão" (SW, VI, 328). Entendo que a dimensão "histórica" do saber exigida do intelectual só possa ser cumprida por meio deste exercício reflexivo da razão, elaborado por Kant na Introdução da terceira Crítica - cuja leitura parece constituir uma herança kantiana que Fichte vai reelaborar em vista de seu projeto filosófico.

Assim, aquela tarefa de diagnóstico do presente (correlata e complementar a uma "filosofia da história") será essencial ao exercício de crítica da razão para Fichte; de tal modo que talvez possamos afirmar que, dentre as pretensões da $W$ - $L$, o exercício de crítica da razão (por meio de uma elaboração cuidadosa do papel da “reflexão") se desdobra em crítica política, dando um inédito e ousado sentido para o "primado prático da razão" em Fichte.

Se me permitem uma analogia remota, tudo se passa como se, também para Fichte, o filósofo devesse voltar à caverna e cumprir sua obrigação política - que não se confunde com a atividade própria do político. Mas há uma diferença decisiva: doravante, o filósofo não pode pretender ter apreendido pelo nous a ideia (de justiça, por exemplo) e, por isso mesmo, pretender realizar imediata e coercitivamente o ideal no real. Em vez disso, cabe a ele "refletir" em vista dos fins da razão, sem a pretensão de determinar a empiria, mas, como que indicar o universal à distância. Neste diagnóstico, seu juízo partilha a mesma pretensão daquele juízo estético: “Este edifício é belo" (assintótico ou, por assim dizer, “regulador”, mas nunca determinante).

Em suma, a meu ver, o que Fichte designa como "tarefa do intelectual" nas Preleções, antes de ser mera expressão anódina e estritamente vinculada às pressões circunstanciais do momento (Oncina e Ramos Valera, 2002 pp.7-24), pode ser lida à luz de um traço decisivo de sua filosofia. O viés "reflexivo" da razão, presente tanto nas exposições especulativas de sua filosofia, quanto (mais enfaticamente, talvez) nos textos de "filosofia prática", ${ }^{10}$ parece-me constituir uma premissa esclarecedora do saber tripartite designado ao intelectual.

V

Para concluir, retomo sumariamente os aspectos centrais de minha exposição. Penso ter oferecido argumentos em favor da vinculação entre certas posições

10 Sobre a importância do ideal "regulador" e seu papel na filosofia prática de Fichte em lena, cf. Frederick Beiser (2016, p.56): "Se, então, Fichte des-hipostasiou a filosofia crítica, ele transformou a ideia do sumo bem de um princípio constitutivo para um princípio regulador. Antes de ser um objeto de crença, seria um objetivo para a ação. Esta transformação já se completa em Algumas preleçães sobre a destinação do sábio, nas quais o sumo bem se torna um ideal da perfeição social e política". 
assumidas por Fiche no "Plano dedutivo" acerca da universidade e da educação, a determinação da "tarefa do intelectual" como um compromisso entre razão e história, e, por fim, um dos aspectos mais essenciais da razão para Fichte: a reflexão.

Assim, as teses do "Plano dedutivo" (de que o ensino universitário deve ser articulado com os outros níveis de ensino, o método "dialógico" em substituição da reprodução mecânica de manuais, e a necessidade de uma interação entre professores na forma de seminários), a meu ver, são teses que decorrem de um diagnóstico do presente conforme o que se exige do intelectual nas Preleções de lena. Uma das condições de possibilidade para o exercício dessa tarefa (que só pode resultar de uma articulação entre saber "filosófico", "histórico-filosófico" e "histórico") parece pressupor, por sua vez, a legitimidade transcendental daquele uso reflexivo do juízo - incorporado por Fichte a partir de sua leitura da Crítica do juízo.

Se estas análises estiverem corretas, a dupla vinculação que pretendi articular aqui pode sugerir um possível lugar sistemático para a educação em Fichte; particularmente, no que diz respeito ao modo como devemos interpretar a noção de "dedução" presente no título do projeto rejeitado por Humboldt. Antes de remeter à inferência silogística ou ao cálculo matemático (aos quais Fichte faz referência explícita em textos de lena), ${ }^{11}$ seu sentido parece recuperar, ainda que implicitamente, outro uso da razão. Mesmo abstendo-nos de determinar o empírico pelos princípios últimos da razão, de "legislar" sobre o espírito humano, nem por isso devemos nos resignar à tarefa de meros "cronistas" do espírito humano, absortos ao casuísmo do tempo (SW, I, 77). Para empreender a tarefa de "historiadores" do espírito humano, será preciso "refletir" e, então, "deduzir" adquire um sentido próprio que pode ser elucidado partir da leitura feita por Fichte da terceira Crítica.

Por esta via, eu posso afirmar que estaria previsto um lugar sistemático para a educação na filosofia de Fichte, como expressão da tarefa do intelectual de dever pensar possíveis mediações entre o empírico e o transcendental; o filosófico e o histórico - e, para tanto, o exercício reflexivo da razão se torna central.

Contudo, pelo menos uma objeção poderia ser colocada: o que dizer de tantas outras afirmações, muito menos emancipatórias, e claramente autoritárias, enunciadas no "Plano dedutivo"?

A partir de minhas análises, posso dizer o seguinte. Na medida mesma em que a "dedução" não deve ser lida em sentido estrito, como argumentei, a tarefa intelectual que cabe ao filósofo parece ser muito mais arriscada. Liberto da segurança do "cálculo", o esforço para diagnosticar o presente e ler o sentido da história, que este esforço parece pressupor para Fichte, talvez exija assumir mais riscos.

A meu ver, Fichte assumiu corajosamente esta tarefa e, com isso, pode ter

11 Não por acaso, ele será criticado no círculo romântico por tentar, supostamente, reduzir a razão a este sentido “dedutivo" estrito (Millán, 2016, p.317). 
incorrido em "erros". Mas seus possíveis erros não devem nos impedir de enxergar algum "acerto". Nesse sentido, entendo que as teses do "Plano", que analisei acima, mostram o quanto ele pressentiu, e muito claramente, a necessidade de se repensar a função e o sentido da instituição universitária de seu tempo. Desse modo, a influência decisiva de Kant (que ainda pensava uma separação entre ensino e pesquisa), não impediu que Fichte pressentisse a necessidade de unir ensino e pesquisa.

Para retomar meu ponto de partida, aquela impressão inicial de leitura pode ser afastada, desde que seu "plano dedutivo" seja inserido num contexto sistemático e conceitual mais preciso. Assim, se minha hipótese estiver correta, nem devemos confundir considerações circunstanciais com um diagnóstico histórico - próprio à tarefa do intelectual -, nem assumir, precipitadamente, que a elaboração de um "plano dedutivo" só possa designar, para Fichte, a determinação do empírico pela razão. Em outra direção, a tarefa própria ao intelectual exige um esforço de "reflexão", pelo qual conhecimento filosófico e histórico devem se articular num modo que não se reduz à mera "inferência"; ou, para usar um vocabulário kantiano (apropriado por Fichte), como “determinação”, mas como “reflexão”. Tudo somado, o embate polêmico com Schleiermacher pode ser retomado sob outra perspectiva.

Não creio que todas as posições de Fichte no "Plano dedutivo" sejam respostas circunstanciais a uma demanda, evidentemente, circunstancial. Por outro lado, contrariamente à provocação de Schleiermacher, também não considero legítimo censurar Fichte como se, presunçosamente, tivesse pretendido “deduzir" uma universidade da $W$ - $L$. Sua coerência - implicada pela compreensão sistemática do saber - não precisa ser reduzida a tanto. Não estou exigindo do teólogo, este adversário voraz de Fichte (notadamente, durante o reitorado desse último na universidade de Berlim), o cuidado de uma ponderação própria ao seu intérprete no papel de historiador da filosofia; mas tentando afastar uma caricatura, tão difundida, e que talvez - impeça, ainda hoje, de se pensar com Fichte.

\section{Referências}

Beiser, F. (2016). “Fichte and the French Revolution”. In: The Cambridge Companion to Fichte (pp. 38-64). Cambridge: Cambridge University Press.

Breazeale, D. (2001). "Inference, intuition, and imagination: on the methodology and method of the first Jena Wissenschaftslehre". In: New essays in Fichte's Foudation of the Entire Doctrine of Scientific Knowledge (pp. 19-36). Nova lorque: Humanity Books.

Ferrer, D. (2005). Filosofia transcendental e universidade: o plano dedutivo para um instituto de ensino superior a estabelecer em Berlim de Fichte. Revista Filosófica de Coimbra, 14(28), 275-300.

Fichte, J.G. (1971). Fichtes Werke. Edição de I.H. Fichte. Berlim: Walter de Gruyter \& Co (11 volumes). 
Kant, I. (1959). Kritik der Urteilskraft. Hamburg: Feliz Meiner.

Kant, I. (1995). Duas introduções à Crítica do Juízo. Terra, R. (org.). São Paulo: Iluminuras.

Kant, I. (2016). Crítica da faculdade de julgar. Tradução de F. C. Mattos. Petrópolis: Vozes: Bragança Paulista: Editora Universitária São Francisco.

Léon, X. (1959). Fichte et son temps. Vol. II “Fichte à Berlin" (1799-1813) Paris: Armand Colin.

Longuenesse, B. (1993). Kant et le pouvoir de juger. Paris: PUF.

Millán, E. (2016). “Fichte and Early German Romantic Philosophy”. In: The Cambridge Companion to Fichte (pp.306-325). Cambridge: Cambridge University Press.

Oncina, F. \& Ramos Valera, M. (2002). “Introducción”. In: Algunas lecciones sobre el destino del sábio (pp. 7-24). Madrid: Ediciones Istimo.

Radrizzani, I. (2016). “The Wissenschaftslehre and historical Engagement”. In: The Cambridge Companion to Fichte (pp. 222-247). Cambridge: Cambridge University Press.

Schleiermacher, F. (1996). Gelegentliche Gedanken Über Universitäten in Deutschen Sinn. Frankfurt: Deutscher Klassiker Verlag. 